\title{
MiR-146a-5p targeting SMAD4 and TRAF6 inhibits adipogenensis through TGF- $\beta$ and AKT/mTORC1 signal pathways in porcine intramuscular preadipocytes
}

\author{
Que Zhang ${ }^{\dagger}$, Rui Cai ${ }^{\dagger}$, Guorong Tang, Wanrong Zhang and Weijun Pang ${ }^{*}$
}

\begin{abstract}
Background: Intramuscular fat (IMF) content is a vital parameter for assessing pork quality. Increasing evidence has shown that microRNAs (miRNAs) play an important role in regulating porcine IMF deposition. Here, a novel miRNA implicated in porcine IMF adipogenesis was found, and its effect and regulatory mechanism were further explored with respect to intramuscular preadipocyte proliferation and differentiation.

Results: By porcine adipose tissue miRNA sequencing analysis, we found that miR-146a-5p is a potential regulator of porcine IMF adipogenesis. Further studies showed that miR-146a-5p mimics inhibited porcine intramuscular preadipocyte proliferation and differentiation, while the miR-146a-5p inhibitor promoted cell proliferation and adipogenic differentiation. Mechanistically, miR-146a-5p suppressed cell proliferation by directly targeting SMAD family member 4 (SMAD4) to attenuate TGF- $\beta$ signaling. Moreover, miR-146a-5p inhibited the differentiation of intramuscular preadipocytes by targeting TNF receptor-associated factor 6 (TRAF6) to weaken the AKT/mTORC1 signaling downstream of the TRAF6 pathway.

Conclusions: MiR-146a-5p targets SMAD4 and TRAF6 to inhibit porcine intramuscular adipogenesis by attenuating TGF- $\beta$ and AKT/mTORC1 signaling, respectively. These findings provide a novel miRNA biomarker for regulating intramuscular adipogenesis to promote pork quality.
\end{abstract}

Keywords: Adipogenesis, AKT/mTORC1 signal pathway, MiR-146a-5p, Porcine intramuscular fat, SMAD4, TGF- $\beta$ signal pathway, TRAF6

\section{Background}

Intramuscular fat (IMF) content is implicated in pork tenderness, flavor, and juiciness, and is an important indicator for assessing pork quality [1, 2]. Therefore, proper ways to increase IMF content and improve pork quality has become an important topic in recent years [3]. The deposition of IMF is achieved through the

\footnotetext{
* Correspondence: pwj1226@nwsuaf.edu.cn

${ }^{\dagger}$ Que Zhang and Rui Cai contributed equally to this work.

Laboratory of Animal Fat Deposition and Muscle Development, College of Animal Science and Technology, Northwest A\&F University, Yangling 712100, Shaanxi, China
}

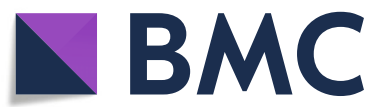

C C The Author(s). 2021 Open Access This article is licensed under a Creative Commons Attribution 4.0 International License, which permits use, sharing, adaptation, distribution and reproduction in any medium or format, as long as you give appropriate credit to the original author(s) and the source, provide a link to the Creative Commons licence, and indicate if changes were made. The images or other third party material in this article are included in the article's Creative Commons licence, unless indicated otherwise in a credit line to the material. If material is not included in the article's Creative Commons licence and your intended use is not permitted by statutory regulation or exceeds the permitted use, you will need to obtain permission directly from the copyright holder. To view a copy of this licence, visit http://creativecommons.org/licenses/by/4.0/. The Creative Commons Public Domain Dedication waiver (http://creativecommons.org/publicdomain/zero/1.0/) applies to the data made available in this article, unless otherwise stated in a credit line to the data. pocytes [4]. The proliferation of preadipocytes is regulated by differential expression of cell cycle regulators, including cyclin-dependent kinases (CDKs), CDK inhibitors (CKIs), and other transcription factors [5]. Similarly, the preadipocyte differentiation process also involves many regulatory factors, including the peroxisome proliferator-activated receptor $\gamma(P P A R \gamma)$, CCAAT/enhancer binding protein $(C / E B P)$ family, fatty acid binding protein 4 (FABP4), and lipoprotein lipase $(L P L)$ [6]. However, besides the above key genes, many miRNAs identified by RNA-seq are also 
involved in the regulation of porcine IMF content, and their functions and mechanisms require further study.

miRNAs are small, evolutionarily conserved non-coding RNAs that have an important function in regulating gene expression. miRNAs function generally by binding target genes that match their "seed sequences" to suppress or degrade target gene mRNAs after transcription and coordinate normal processes, including cellular proliferation, differentiation and apoptosis [7, 8]. Increasing evidence has shown that miRNAs, including miR-206 [9], miR-1495p [10] and miR-204-5p [11], play key roles in preadipocyte proliferation and differentiation. Moreover, many miRNAs are differentially expressed in porcine adipose tissue during different developmental stages and have been studied using transcriptome sequencing technology [12]. We therefore speculated that these miRNAs may be key regulators of porcine IMF deposition through their target genes.

Classical TGF- $\beta /$ SMAD signaling regulates cell proliferation, differentiation, migration and growth. SMAD4 is an important transmission medium that transduces extracellular signals, including TGF- $\beta$ and BMP, to the nucleus [13-15]. It has been reported in the literature that SMAD4 regulates the proliferation and migration of A549 cells [16], dihydromyricetin inhibits the proliferation of human choriocarcinoma JAR cells via downregulation of SMAD4 expression [17], and miR-224 mediates the proliferation of HCT116 cells by targeting SMAD4 [18]. Although SMAD4 has been discovered and studied in the proliferation of different cell types, it needs to be further explored whether SMAD4 is implicated in proliferation of porcine intramuscular preadipocytes.

TRAF6 is an adapter protein that possesses E3 ubiquitin ligase activity [19] and plays an important role in intracellular signal transduction [20]. For instance, TRAF6 is a direct ubiquitinase of the serine/threonine kinase AKT and promotes AKT phosphorylation and activation [21, 22]. AKT is a node at the junction of many major intracellular signaling pathways [23] and plays an essential role in adipocyte differentiation. Preadipocytes that lack Akt exhibit differentiation defects because they fail to induce PPARY expression at the beginning of the adipogenesis program [24-26]. Furthermore, mTORC1, a major downstream signaling regulator of AKT, is a key regulator of mRNA translation and cell growth [27]. Several studies have found that mTORC1 activity is required for proper preadipocyte differentiation [28-30]. However, whether TRAF6 acts as an miRNA target to regulate the activation of the AKT/mTORC1 signaling pathway, thereby affecting porcine intramuscular preadipocyte differentiation, remains unknown.

In this study, based on a published miRNA sequencing analysis of adipose and muscle tissue at four developmental stages of pigs, at one, 30, 90 and 240 days of age
[31], we found that miR-146a-5p showed significant expression differences in adipose tissue at all stages, but was not differentially expressed in muscle tissue at a later stage of growth. These findings implying that miR146a-5p may have a key effect on IMF deposition, and our results reveal that miR-146a-5p inhibits intramuscular preadipocyte proliferation and differentiation by targeting SMAD4 and TRAF6 through TGF- $\beta$ and AKT/ mTORC1 signaling pathways. Thus, miR-146a-5p is a novel key regulator of pig IMF deposition.

\section{Methods}

\section{Animal and sample collection}

Piglets ( 3 days old) were provided by the animal experiment animal ranch of Northwest A\&F University. According to the regulations of the Animal Protection Committee of Northwest A\&F University, all pigs were killed in the slaughterhouse. Dissect the heart, liver, spleen, lung, kidney, longissimus dorsi muscle (LD) and subcutaneous white adipose tissue (SWAT), and rinse with phosphate buffered saline (PBS). The samples used for real-time quantitative PCR (RT-qPCR) were frozen and stored in liquid nitrogen.

\section{Isolation and culture of porcine intramuscular preadipocytes}

At 3 days old piglets were sacrificed, the intramuscular preadipocytes in LD were extracted as previously described [32]. Cells were re-suspended in DMEM/F12 and plated at a density $6 \times 10^{5}$ per $60-\mathrm{mm}$ culture dish (Fig. S1A), and cultured in a $5 \% \mathrm{CO}_{2}$ incubator at $37^{\circ} \mathrm{C}$. When the cells grow to confluence (Fig. S1C), the medium was changed with adipogenic induction medium, which is the DMEM/F12 supplement with $10 \%$ FBS, $100 \mathrm{U} / \mathrm{mL}$ penicillin-streptomycin, $\quad 0.5 \mathrm{mmol} / \mathrm{L} \quad \mathrm{IBMX}, \quad 1 \mathrm{nmol} / \mathrm{L}$ DEX, and $5 \mathrm{ng} / \mathrm{mL}$ insulin (IBMX, DEX and insulin were purchased from Sigma).

\section{Transfection of mimics/inhibitor NC and miR-146a-5p mimic/inhibitor}

Porcine intramuscular preadipocytes were seeded in 6well, 12-well, 24-well or 96-well plates. When detecting cell proliferation, miR-146a-5p mimics or mimics negative control (MNC) (Ribobio, China) were transfected (50 $\mathrm{nmol} / \mathrm{L}$ ) when the cell density reached $50-60 \%$ (Fig. S1B). During transfection, X-tremeGENE siRNA Transfection Reagent (Roche, USA) was mixed with Opti-MEM medium (Gibco, USA) for $5 \mathrm{~min}$, then the two mixtures were mixed for $20 \mathrm{~min}$ and added to the cell culture medium, and the medium was replaced with fresh culture after $12 \mathrm{~h}$. Cells were harvested $24 \mathrm{~h}$ after transfection for cell proliferation studies. When transfected with miR146a-5p inhibitor, the method is the same as above, but the final concentration of miR-146a-5p inhibitor was 100 
$\mathrm{nmol} / \mathrm{L}$. For the differentiation of preadipocytes, the cells were transfected when the cell density reached $70 \%$. When cells reached confluence after transfection, adipogenic differentiation was induced by switching to differentiation medium.

\section{Total RNA extraction, RNA reverse transcription and RT- qPCR}

After obtaining the cells, the cells were lysed with Trizol reagent (TakaRa, Otsu, Japan) and the total RNA in the cells was extracted. The concentration of total RNA was measured by the NanoDrop 2000 (Thermo, Waltham, MA, USA). Then the reverse transcription kit (TakaRa, Otsu, Japan) was used to synthesize cDNA. The specific reverse transcription primers and procedures were used for miRNA inversion. About real-time quantitative PCR, the SYBR green kit was used and three replicates were set up, and then the PCR reaction was performed on the Bio-Rad iQTM5 system. GAPDH was used as the internal reference for all genes for standardized analysis. But when analyzing miR-146a-5p levels, U6 was used as an internal reference. Table 1 shows the primer sequences used for $\mathrm{qPCR}$. The primer sequences used for qPCR were shown in Table 1 .

\section{Western blots}

Cell samples were lysed using radio immunoprecipitation assay (RIPA) buffer (Beyotime, China) supplemented with protease inhibitor (Pierce, WA, USA) and total protein was extracted. The total protein samples were separated by electrophoresis in SDS-polyacrylamide gel. Then transferred it to PVDF membranes (Millipore, Bedford, MA, USA). After blocking the membrane in 5\% skim milk for $2 \mathrm{~h}$, the primary antibody was incubated overnight $\left(4^{\circ} \mathrm{C}\right)$ and the secondary antibody was incubated for $1.5 \mathrm{~h}\left(4^{\circ} \mathrm{C}\right)$. Protein bands were exposed with chemiluminescent reagents (Millipore, Bedford, MA, USA) and quantified using Image J. Following primary antibodies were used: Cyclin D (1:100; Santa Cruz, USA), Cyclin E (1:100; Santa
Cruz, USA), PCNA (1:1000; CST, USA), P21 (1:100; Santa Cruz, USA), C/EBP $\beta$ (1:100; Santa Cruz, USA), PPARY (1:100; Santa Cruz, USA), FABP4 (1:100; Santa Cruz Biotechnology, Dallas, TX, USA), TRAF6 (1:500; Aviva Systems Biology, USA), SMAD4 (1:100; Santa Cruz, USA), $\beta$-actin (1:1000; Santa Cruz Biotechnology, Dallas, TX, USA), AKT (1:2000; Cell Signaling Technology, USA), p-AKT (1:2000; Cell Signaling Technology, USA), mTORC1 (1:2000; Cell Signaling Technology, USA), p-mTORC1 (1:2000; Cell Signaling Technology, USA),The secondary antibodies were antirabbit, anti-goat and anti-mouse antibodies (1:3000; Santa Cruz Biotechnology, Dallas, TX, USA). The targeted proteins were detected using the Gel Doc XR System (Bio-Rad, Hercules, CA, USA) as the instructions of the manufacturer.

\section{Target prediction and luciferase activity assay}

The target genes of miR-146a-5p were predicted with Target-Scan 7.0. For the dual-reporter assay, we constructed a wild-type and mutant psiCHECK-2-reporter vector containing the target genes SMAD4 and TRAF6 3' UTR region (TongYong, Anhui, China). HEK293T was seeded in a 48-well plate and cotransfected with miRNA mimics or the negative control with psiCHECK-2-SMAD4 (or TRAF6)-reporter vector or mutant vector. After $48 \mathrm{~h}$ of transfection, the relative luciferase activity of Renilla compared with firefly was measured.

\section{EDU imaging assay}

We used the Cell-Light ${ }^{\mathrm{mm}}$ EdU Apollo ${ }^{\circ} 567$ In Vitro Imaging Kit and configured the mixed solution according to the instructions. The preadipocytes in the normal growth stage were treated with $50 \mu \mathrm{mol} / \mathrm{L}$ EDU medium for $2 \mathrm{~h}$. After the cells were fixed with $4 \%$ paraformaldehyde, they were stained with Apollo reaction solution. Then cell nucleus was stained with Hoechst. Nikon TE2000 microscope (Nikon, Tokyo, Japan) was used to take pictures, and the data was analyzed using Image J.

Table 1 Primer sequences used in this study

\begin{tabular}{|c|c|c|c|}
\hline Gene & Accession number & Forward sequences $\left(5^{\prime} \rightarrow 3^{\prime}\right)$ & Reverse sequences $\left(5^{\prime} \rightarrow 3^{\prime}\right)$ \\
\hline Cyclin B & NM_001285465.1 & GCATCTITGCTGAGATGGTGAC & AATCTTGCCTGGCCCACTTA \\
\hline Cyclin D & NM_001123097.1 & GGCCCTCAAGAGCGTAAGAG & GTCTCTCGATCAGTTCGGGC \\
\hline Cyclin $E$ & NM_001044621.3 & GCCAGACTATAAGCCCTACCC & GGACCGGGTTACACTTCAGG \\
\hline$P 21$ & XM_013977858.2 & ACGTCTCAGGAGGACCATGT & AGAAGATCAGCCGGCGTTG \\
\hline$C / E B P \beta$ & NM_001199889.1 & TCCGATCTCTTCTCCGACGA & CAGGCTCACGTAGCCGTATT \\
\hline PPARY & NM_001354666.3 & AGGACTACCAAAGTGCCATCAAA & GAGGCTITATCCCCACAGACAC \\
\hline FABP4 & NM_001002817.1 & TGAAAGAAGTGGGAGTGGGC & CTGGCCCAATTTGAAGGCAA \\
\hline SMAD4 & NM_008540.3 & TCACTATGAGCGGGTTGTCTC & TCCTTCAGTGGGTAAGGACG \\
\hline TRAF6 & NM_001105286.1 & GGGAACGATACGCCTTACAA & СTCTGTCTTAGGGCGTCCAG \\
\hline GAPDH & KJ786424 & AGGTCGGAGTGAACGGATTTG & AGGTCGGAGTGAACGGATTTG \\
\hline
\end{tabular}




\section{Cell counting kit 8 (CCK8) analysis}

Preadipocytes were seeded to 96-well plate in a number of $4 \times 10^{3}$ cells. Preadipocytes were transfected with miR-146a-5p mimics/inhibitor or mimics/inhibitor negative control with 3 repetitions. After treatment for $24 \mathrm{~h}$ we switched the cells to culture medium containing $10 \%$ CCK solution for $2 \mathrm{~h}$ at $37^{\circ} \mathrm{C}$ followed by measuring absorbance at $490 \mathrm{~nm}$.

\section{Flow cytometry}

Preadipocytes were seeded in 6- well culture plate at a density of $4 \times 10^{5}$ cells per well. Cells were transfected with miR-146a-5p mimic or inhibitor for $24 \mathrm{~h}$. After washed three times with PBS, cells were fixed with $70 \%$ alcohol overnight at $-20^{\circ} \mathrm{C}$ followed by being treated with $1 \mathrm{mg} / \mathrm{mL}$ RNAase at $37^{\circ} \mathrm{C}$ for $40 \mathrm{~min}$, and stained with $50 \mathrm{mg} / \mathrm{mL}$ propidium iodide (PI) at $4{ }^{\circ} \mathrm{C}$ for $1 \mathrm{~h}$. The samples were detected using a FACS Calibur flow cytometer (Becton Dickinson, Franklin Lakes, NJ, USA). The proliferation index (PI) shows the proportion of mitotic cells among the 10,000 cells examined.

\section{Oil Red O, BODIPY and AdipoRed staining}

For Oil Red O staining, cells were fixed in a 4\% paraformaldehyde solution for $30 \mathrm{~min}$, induced with $60 \%$ Oil Red O for $30 \mathrm{~min}$, and washed three times with PBS, and then the cells were visualized by phase-contrast microscope (IS-Elements software, Nikon ECLIPSE, Tokyo, Japan). Oil Red O was extracted with $100 \%$ isopropanol, and its relative concentration was determined by measuring the absorbance at $510 \mathrm{~nm}$. After being fixed in 4\% paraformaldehyde solution for $15 \mathrm{~min}$, cells were stained with BODIPY $(1 \mu \mathrm{g} / \mathrm{mL}$; Life Technologies, Carlsbad, CA, USA) or AdipoRed $(30 \mu \mathrm{L} /$ $\mathrm{mL}$; Lonza, USA) for $20 \mathrm{~min}$; the sections were washed with PBS three times for $5 \mathrm{~min}$ each. For nuclear visualization, DAPI (4',6-diamidino-2-phenylindole; Roche) was incubated for $10 \mathrm{~min}$, then the section was rinsed with PBS. After treatment, the sections were observed under fluorescence microscope (Nikon, Tokyo, Japan).

\section{Bioinformatics analysis}

The sequences of miRNAs were searched for at miRBase (http://www.mirbase.org/). Sequence alignment using MAGA software. The 3' UTR sequences of E2F3 and P55PIK were downloaded from NCBI. Target genes of miRNA were predicted by TargetScan 7.0 Human (http://www.targetscan.org).

\section{Statistical analysis}

All charts were created using GraphPad Prism 6.0 and the data represent the mean \pm SEM. The significance of differences between the groups was assessed using the Student's $t$ test or one-way analysis (*, $P<0.05$; **, $P<0.01)$.

\section{Results}

MiR-146a-5p is a potential regulator of porcine IMF adipogenesis

To identify miRNAs related to porcine IMF deposition, miRNA sequencing data were analyzed. As shown in the heat map, the levels of miR-146a-5p in the $30 \mathrm{~d}, 90 \mathrm{~d}$, and $240 \mathrm{~d}$ porcine adipose tissue were significantly higher than those in the $0 \mathrm{~d}$ piglets (Fig.1a). Moreover, the miR-146a-5p seed sequence in humans, pigs and mice is highly conserved (Fig. 1b). The KEGG pathway analysis predicted that miR-146a-5p is involved in the TGF- $\beta$, AKT and mTORC pathways (Fig. 1c), and the GO term analysis suggested that miR-146a-5p can regulate cell proliferation and fat cell differentiation (Fig. 1d). Furthermore, miR-146a-5p is highly expressed in porcine WAT (Fig. 1e). Most importantly, the levels of miR-146a$5 p$ increased first and then decreased in proliferated and differentiated porcine intramuscular preadipocytes, but they showed an upward trend in the late stage of differentiation (Fig. If and g).

\section{MiR-146a-5p mimics inhibit proliferation of porcine intramuscular preadipocytes}

To investigate the effect of miR-146a-5p on the proliferation of porcine intramuscular preadipocytes, the miR146a-5p mimics and mimics negative control (MNC) were transfected into cells. Compared with the MNC group, the positive cells labeled with EDU and the total number of cells in the mimics group was significantly reduced $(P<0.05)$ (Fig. $2 \mathrm{a}-\mathrm{c})$. In addition, the number of $S$-phase cells was significantly lower in the mimics group than in the MNC group $(P<0.05)$, but the number of cells in the G1-phase was significantly higher than that in the MNC group $(P<0.05)$ (Fig. $2 \mathrm{~d}$ and e). Furthermore, the miR-146a-5p mimics sharply increased the levels of miR-146a-5p $(P<0.05)$, significantly decreased the mRNA levels of cyclin B, cyclin D and cyclin E, whereas it apparently increased the mRNA levels of $\mathrm{p} 21$ $(P<0.05)$ (Fig. $2 f$ and g). Similarly, the miR-146a-5p mimics downregulated the protein levels of cyclin $\mathrm{D}$, cyclin E and PCNA $(P<0.05)$, and $\mathrm{P} 21$ protein tended to be upregulated, but did not reach statistical significance (Fig. $2 \mathrm{~h}$ and i).

\section{MiR-146a-5p inhibitor promotes porcine intramuscular preadipocyte proliferation}

To validate the role of miR-146a-5p inhibitor on the proliferation of porcine intramuscular preadipocytes, inhibitor negative control (INC) and miR-146a-5p inhibitors were transfected into porcine intramuscular preadipocytes. The results indicated that knockdown of miR-146a-5p significantly increased the number of EdU-positive cells, S-phase cells and total cells $(P<$ 0.05) (Fig. 3a-e). The inhibitor effectively decreased 


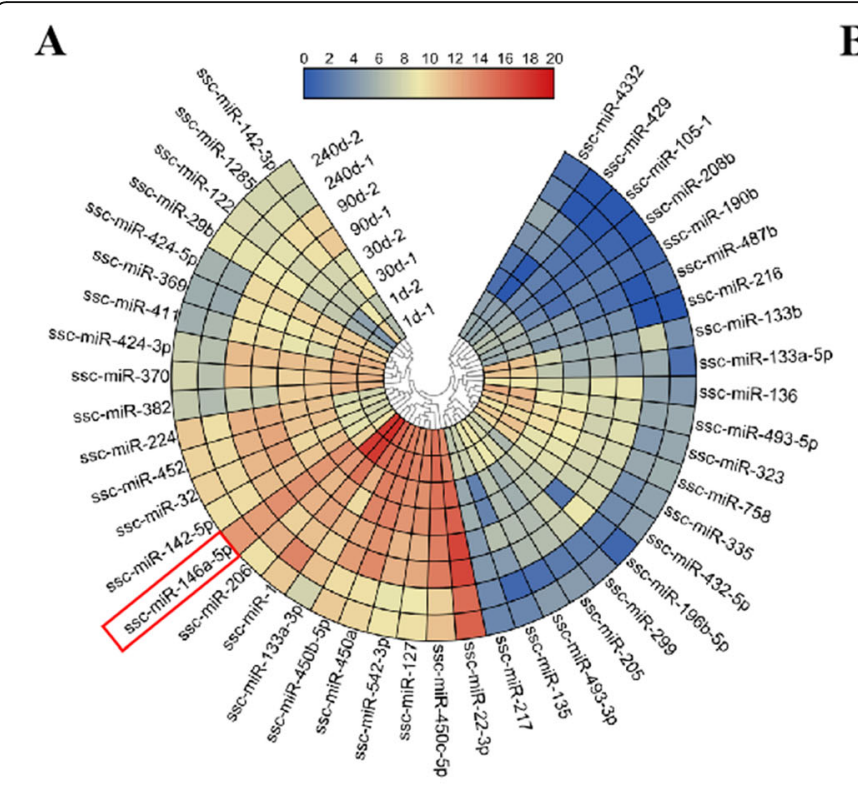

B

C

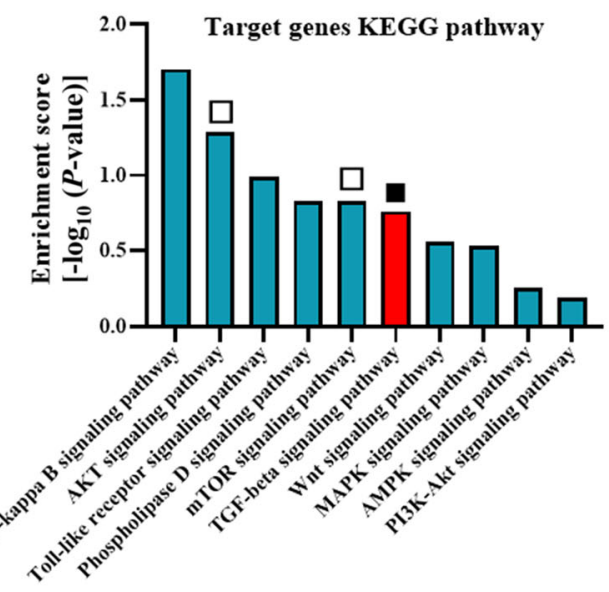

D

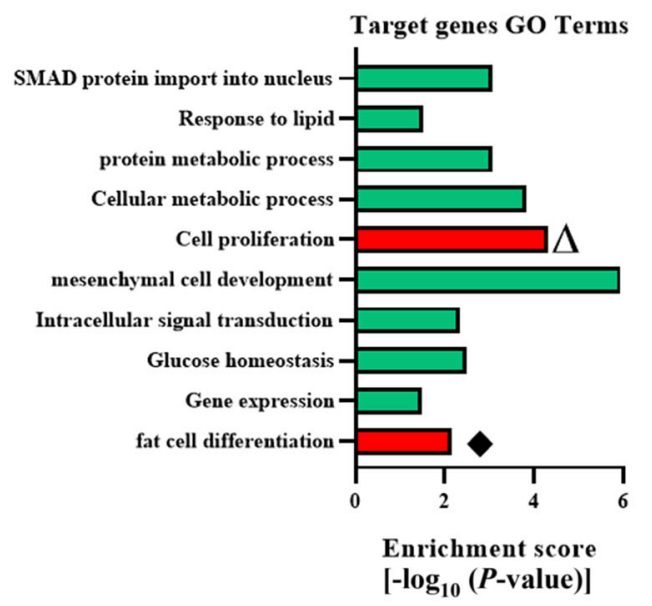

$\mathbf{E}$

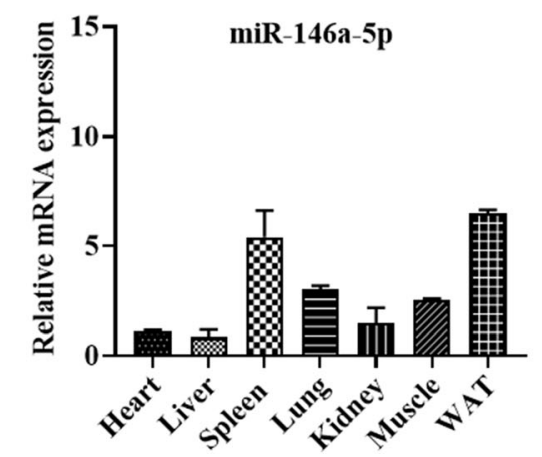

$\mathbf{F}$

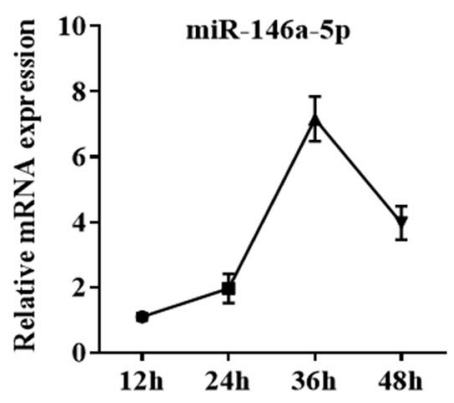

Mature sequence

ssc-miR-146a-5p UGAGAACUGAAUUCCAUGGGUL

mmu-miR-146a-5p UGAGAACUGAAUUCCAUGGGUU

hsa-miR-146a-5p UGAGAACUGAAUUCCAUGGGUU

gga-miR-146a-5p UGAGAACUGAAUUCCAUGGGUU mdo-miR-146a-5p UGAGAACUGAAUUCCAUGGGUU

Fig. 1 MiR-146a-5p is a potential regulator of porcine IMF adipogenesis. a The differential expression analysis heat map of miRNA sequencing data. Different colors represented the relative expression. b Comparation of miR-146a-5p seed sequence from pig, mice and human, etc. c KEGG pathway analysis of the miR-146a-5p target genes. $\mathbf{d}$ GO term analysis of the miR-146a-5p target genes. e Tissue expression profile of miR-146a$5 p$ in pig. $\mathbf{f}$ RT-qPCR was performed to detect the expression of miR-146a-5p in proliferating in porcine intramuscular preadipocytes. $\mathbf{g}$ RT-qPCR analysis of miR-146a-5p expression after inducing adipogenic differentiation. Results are representative of the mean \pm SEM $(n=3)$ 
A

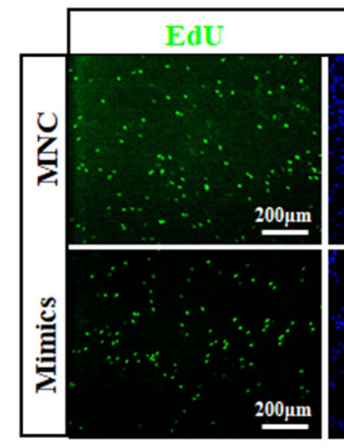

Merge

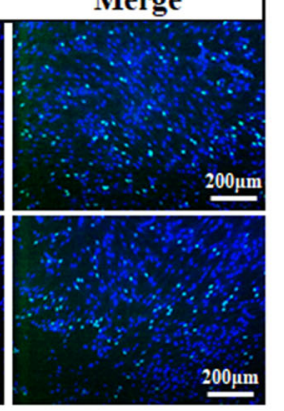

B
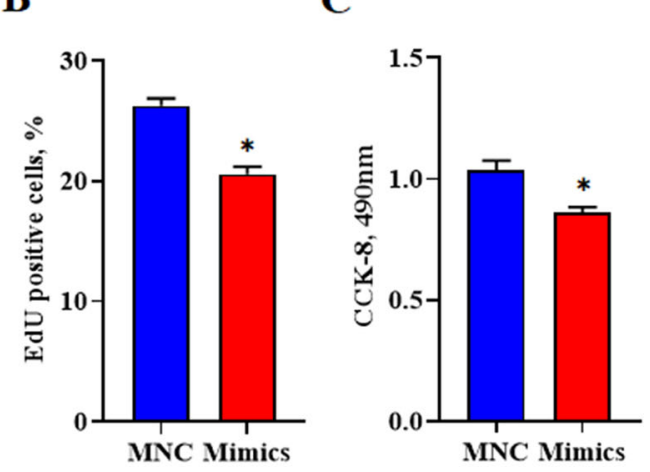

E

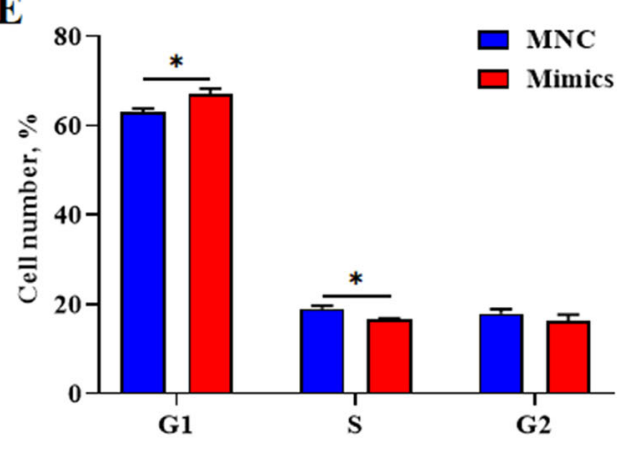

$\mathbf{F}$
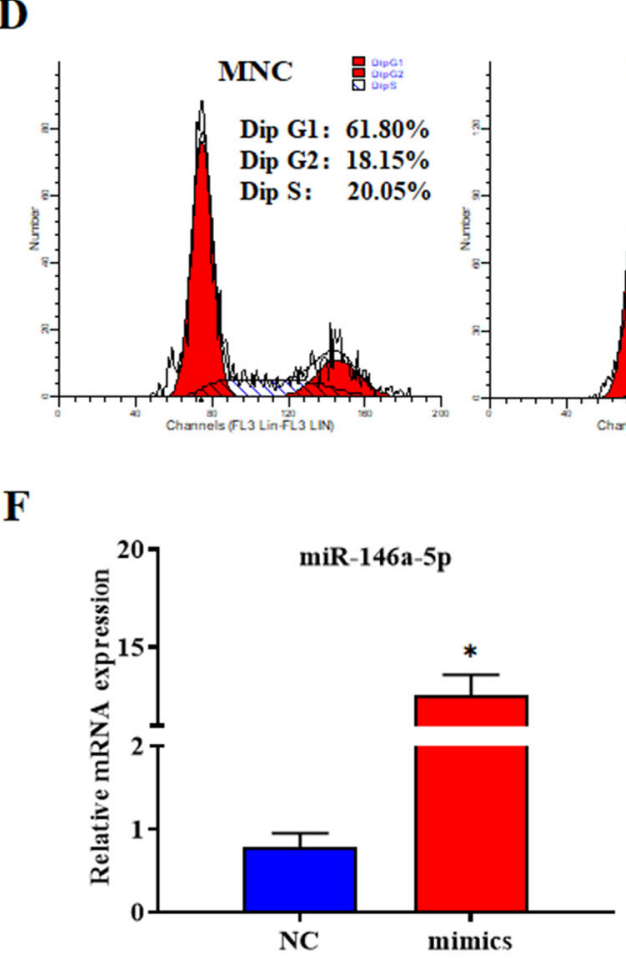

H

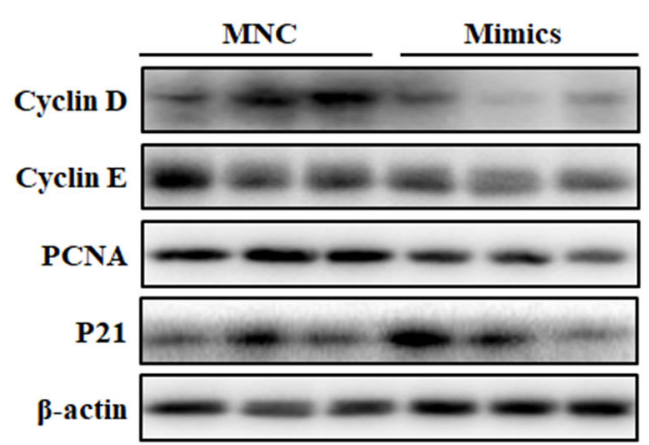

G

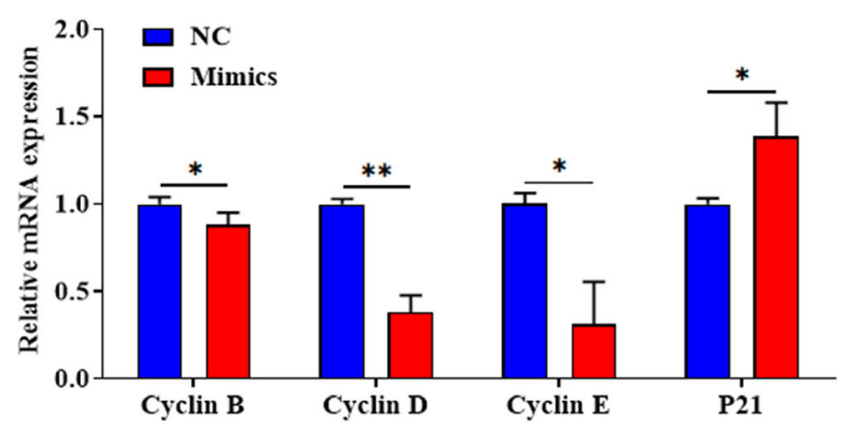

I

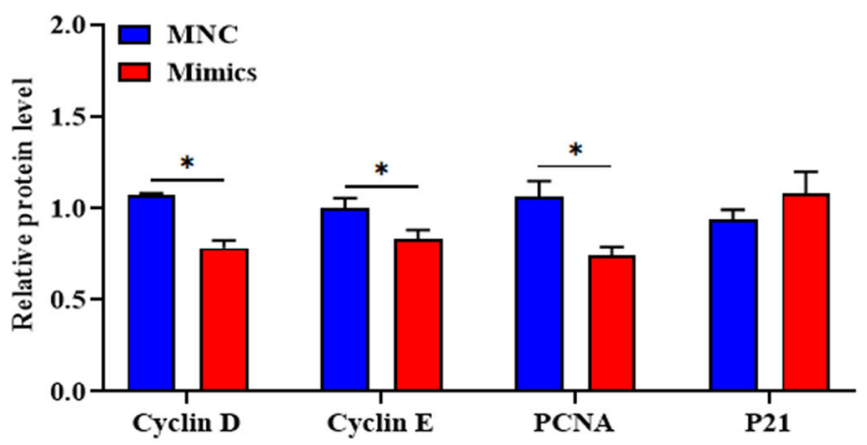

Fig. 2 (See legend on next page.) 
(See figure on previous page.)

Fig. 2 MiR-146a-5p mimics inhibit proliferation of porcine intramuscular preadipocytes. a EdU staining assay. Porcine intramuscular preadipocyte in the S-phase were stained with EdU in red, and cell nuclei were dyed with Hoechst in blue. b Quantification ratio of EdU-positive cells/total cells. c CCK-8 analysis after treatment with miR-146a-5p mimics during porcine intramuscular preadipocyte proliferation. $\mathbf{d}$ Cell cycle analysis of preadipocyte by flow cytometry. e Statistical results of flow cytometry. f Overexpression efficiency of miR-146a-5p mimics after transfection for 24 h. $\mathbf{g}$ RT-qPCR was used to detect the cell cycle genes cyclin B, cyclin D, cyclin E, and p21. $\mathbf{h}$ Western blot analysis of cyclin E, cyclin D, PCNA and p21 after transfection with miR-146a-5p mimics. i Protein quantitative analysis of cyclin E, cyclin D, PCNA and p21. Values are expressed as mean $\pm \operatorname{SEM}(n=3) .{ }^{*}, P<0.05 ;{ }^{*}, P<0.01$, versus MNC

the levels of miR-146a-5p $(P<0.05)$ and increased the mRNA levels of cyclin B, cyclin D, and cyclin E, but reduced the level of p21 $(P<0.05)$ (Fig. 3f and $\mathrm{g}$ ). Meanwhile, the inhibitor upregulated the protein levels of cyclin D and cyclin E, whereas downregulated the protein level of P21 $(P<0.05)$ (Fig. $3 \mathrm{~h}$ and i).

MiR-146a-5p targeting SMAD4 inhibits the proliferation of porcine intramuscular preadipocytes by the TGF- $\beta$ signaling pathway

To further explore the regulatory mechanism of miR146a-5p on porcine intramuscular preadipocyte proliferation, we predicted and verified its target genes and signaling pathways. SMAD4 may be the target gene of miR-146a-5p using TargetScan 7.0 analysis (Fig. 4a and b). The dual-luciferase reporter (DLR) assay results showed that the relative luciferase activity of miR-146a-5p mimics plus SMAD4 WT vector cotreated group was significantly reduced $(P<0.05)$ (Fig. 4c and d). Next, the rescued experiments were carried out. Compared with the mimics group, the number of EDU-positive cells and the total number of cells in the mimics and SMAD4 overexpression vector co-treatment group markedly increased $(P<0.01)$, and rescued or even exceeded the NC group level (Fig. 4e-g). Moreover, $S M A D 4$ overexpression restored the mRNA and protein levels of SMAD4 and cell cycle-related genes $(P<$ 0.05) (Fig. 4h-k). In addition, SMAD4 downstream TGF- $\beta$ signaling was attenuated by mimics, but was rescued upon SMAD4 overexpression $(P<0.05)$ (Fig. $4 \mathrm{j}$ and $\mathrm{k}$ ).

\section{MiR-146a-5p mimics suppress porcine intramuscular preadipocyte differentiation}

To study the effects of miR-146a-5p mimics on the differentiation of porcine intramuscular preadipocytes, we treated cells with MNC and miR-146a-5p mimics, and then induced adipogenic differentiation for 6 days. Compared with the MNC group, the lipid droplets produced by intramuscular adipocytes apparently decreased in the mimics group, and the triglyceride (TG) content also significantly decreased $(P<0.05)$ (Fig. 5a-d). The expression of miR-146a-5p was significantly increased in differentiated intramuscular adipocytes $(P<0.05)$ (Fig. 5e). However, the mRNA and protein levels of $\mathrm{C} / \mathrm{EBP} \beta, \mathrm{PPAR} \gamma$ and FABP4 were both markedly decreased $(P<0.05)$ (Fig. 5f-h).

\section{MiR-146a-5p inhibitor accelerates porcine intramuscular preadipocyte differentiation}

To further validate the role of miR-146a-5p in the differentiation of porcine intramuscular preadipocytes, we carried out the experiments of INC and inhibitor treatment on the cells. Compared with the INC group, the lipid droplets apparently accumulated in intramuscular adipocytes, and the TG content also significantly increased $(P<0.05)$ (Fig. 6a-d). Inhibitor significantly decreased the levels of miR-146a-5p (Fig. 6e), but markedly increased the mRNA levels of $C / E B P \beta, P P A R \gamma$ and FABP4 $(P<0.05)$ (Fig. 6f). Meanwhile the protein levels of $\mathrm{C} / \mathrm{EBP} \beta$ and $\mathrm{PPAR} \gamma$ significantly increased in the treatment group $(P<0.05)$ (Fig. 6 g and $h)$.

MiR-146a-5p targeting TRAF6 inhibits the differentiation of porcine intramuscular preadipocytes via the AKT/ mTORC1 signaling pathway

To further investigate the mechanism by which miR$146 a-5 p$ regulates the differentiation of intramuscular preadipocytes, we explored its target genes and signaling pathways. The online software predicted that miR-146a5 p could be combined with the TRAF6 3' UTR (Fig. 7a and $b)$. The DLR assay results showed that the relative luciferase activity of miR-146a-5p mimics and TRAF6 WT vector co-treated group was significantly reduced $(P<0.05)$ (Fig. 7c and d). The rescued experiments were performed. Compared with the mimics group, the lipid droplets and TG content in the TRAF6 overexpression vector plus mimics co-treated group significantly increased and rescued to the NC group $(P<0.05)$ (Fig. 7eh). Moreover, TRAF6 overexpression rescued the mRNA and protein levels of TRAF6 and adipogenic related genes $(P<0.05)$ (Fig. $7 \mathrm{i}-1)$. AKT/mTORC1 as the important downstream signaling pathway of TRAF6, their phosphorylation levels were significantly decreased in mimics group but increased in co-treated group $(P<0.01)($ Fig. $7 \mathrm{~m}$ and $n$ ).

\section{Discussion}

As a member of the non-coding RNA family, miRNAs have a crucial regulatory role in preadipocyte adipogenesis. 
A
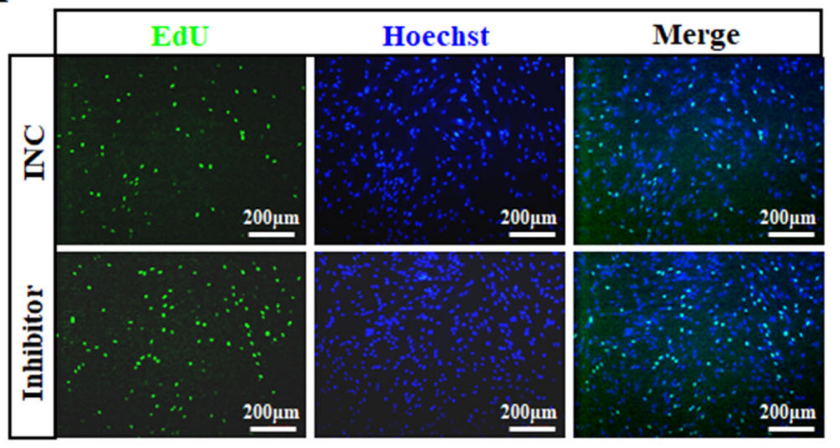

D

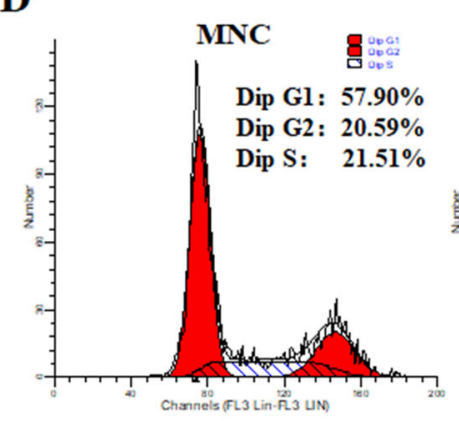

F

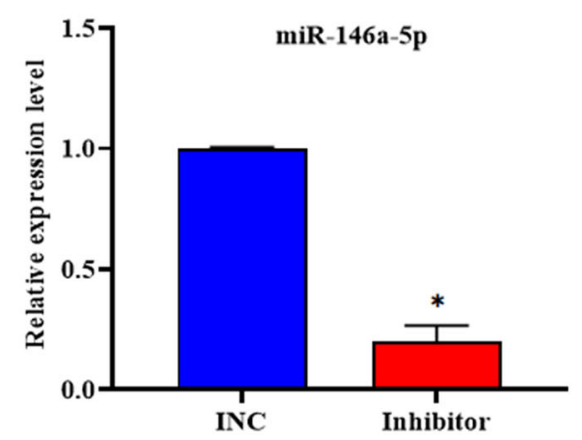

H

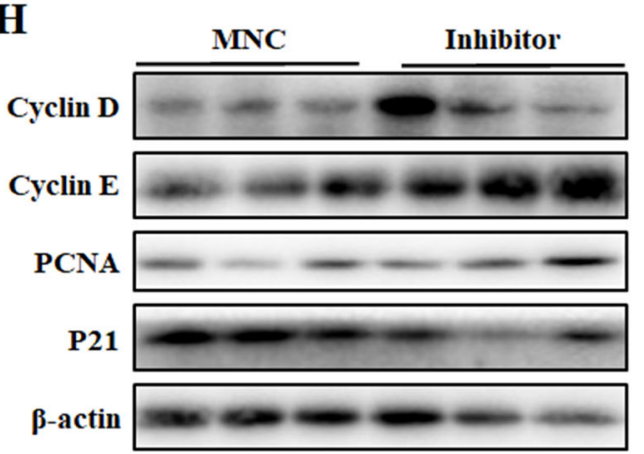

B

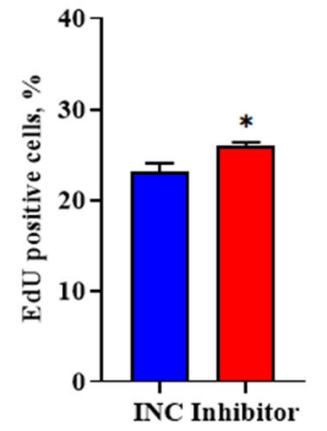

C

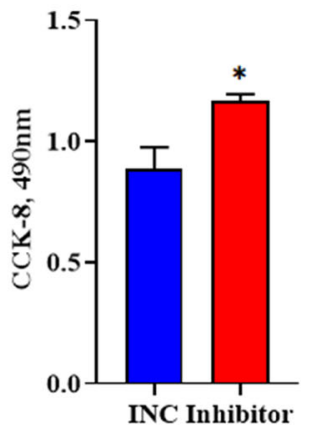

$\mathbf{E}$

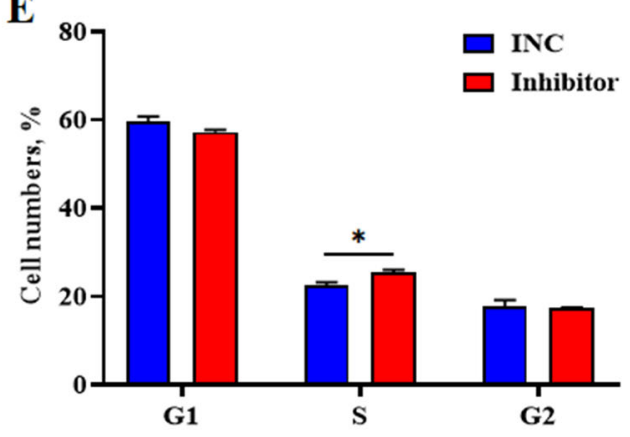

G

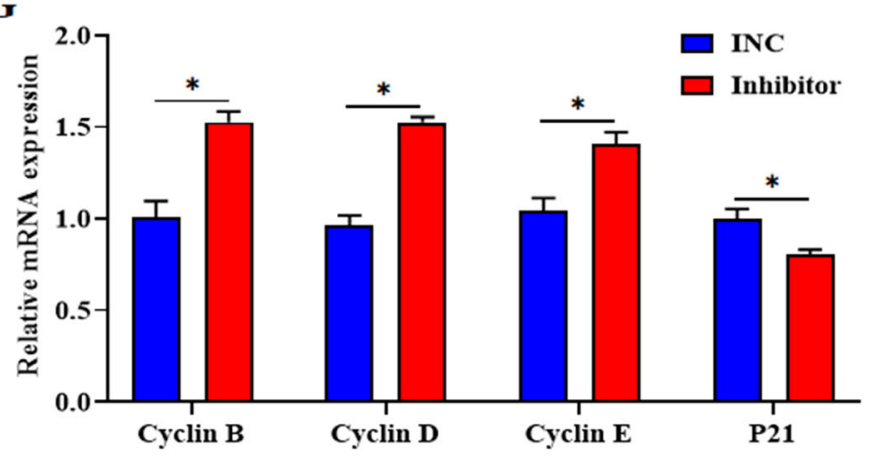

I

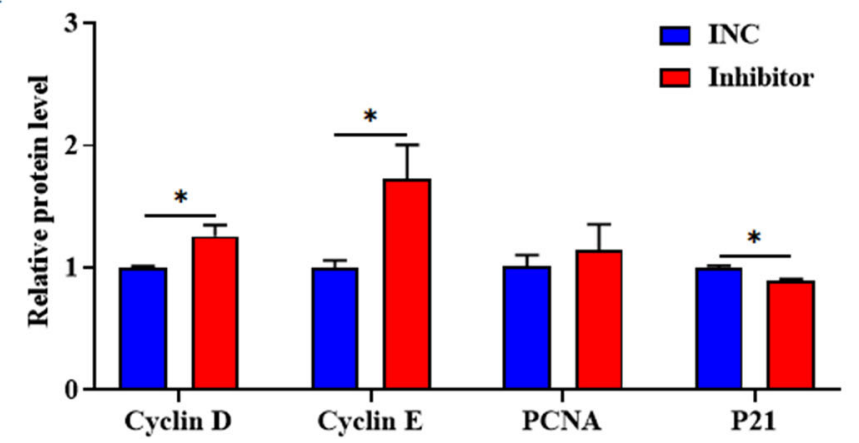

Fig. 3 (See legend on next page.) 
(See figure on previous page.)

Fig. 3 MiR-146a-5p inhibitor promotes porcine intramuscular preadipocyte proliferation. a EdU staining assay. Porcine intramuscular preadipocyte in the S-phase were stained with EdU in red, and cell nuclei were dyed with Hoechst in blue. b Quantification ratio of EdU-positive cells/total cells. c CCK-8 analysis after treatment with miR-146a-5p inhibitor during porcine intramuscular preadipocyte proliferation. $\mathbf{d}$ Cell cycle analysis of preadipocyte by flow cytometry. e Statistical results of flow cytometry. $\mathbf{f}$ Interference efficiency of miR-146a-5p inhibitor after transfection for $24 \mathrm{~h}$. g RT-qPCR was used to detect the cell cycle genes cyclin B, cyclin D, cyclin E, and p21. $\mathbf{h}$ Western blot analysis of cyclin E, cyclin D, PCNA and p21 after transfection with miR-146a-5p inhibitor. i Protein quantitative analysis of cyclin E, cyclin D, PCNA and p21. Values are expressed as the mean $\pm \operatorname{SEM}(n=3) . *{ }^{*}, P<0.05$, versus INC

Based on bioinformatics analysis of miRNA sequencing data, we found that miR-146a-5p was differentially expressed during SWAT deposition in pigs. Further study showed that the miR-146a-5p sequence was highly conserved, and its function was involved in fat cell proliferation and differentiation by TGF- $\beta$ and AKT/mTORC1 signal pathways using KEGG and GO analysis. Moreover, miR146a-5p was highly expressed in porcine white adipose tissue (WAT), and its expression levels first increase and then decrease in proliferated and differentiated porcine intramuscular preadipocytes. Based on the above analysis, we speculated that miR-146a-5p is also implicated in IMF deposition.

It is vital to improve pork quality by controlling the IMF content during pig production. The present study demonstrated that miR-146a-5p plays a crucial role in regulating porcine IMF adipogenesis. miR-146a-5p targets SMAD4 and inhibits porcine intramuscular preadipocyte proliferation by attenuating TGF- $\beta$ signaling and also targets TRAF6 to repress differentiation by weakening $\mathrm{AKT} / \mathrm{mTORC} 1$ signaling. These findings indicate that miR-146a-5p could be a novel negative regulator of porcine IMF deposition.

IMF deposition depends on the proliferation and differentiation of intramuscular preadipocytes. Our results confirmed that miR-146a-5p inhibited intramuscular preadipocyte proliferation by reducing the number of S-phase cells and downregulating the mRNA and protein levels of cyclin B, cyclin D, cyclin E and PCNA, and upregulating the mRNA and protein levels of $\mathrm{p} 21$. Previous studies revealed that miR-146a$5 \mathrm{p}$ promotes lung cancer cell proliferation by targeting claudin-12 [33], and overexpression of miR-146 or knockout of its target gene, notch 1, inhibits mouse neural stem cell proliferation in serum-free medium [34]. Therefore, miR-146a-5p differentially modulates the proliferation of different cell types. Generally, genes and miRNAs have opposite effects on cell proliferation and differentiation. Recent studies have shown that miR-6645 p promotes myoblast proliferation and inhibits myoblast differentiation [35], and miR-429 accelerates proliferation of porcine preadipocytes and represses adipogenic differentiation [36]. Interestingly, in this study, miR-146a-5p repressed both the proliferation and differentiation of intramuscular preadipocytes. Studies have indicated that miR-483 inhibits the proliferation and differentiation of bovine myoblasts [37], and miR-342-5p has been found to restrict osteoblast proliferation and differentiation by inhibiting Bmp7 expression [38]. Therefore, our results are reasonable, due to the complexity of intramuscular preadipocyte biological processes that are regulated by miRNAs.

Generally, miRNAs regulate different biological processes in the same cell through different target genes. Therefore, we predicted the target genes of miR-146a$5 p$ that are involved in cell proliferation and adipogenic differentiation, respectively. During the proliferation phase, we predicted that SMAD4 was the target gene of miR-146a-5p. Recent studies have shown that miR-145$5 \mathrm{p}$ inhibits ovarian epithelial cancer cell proliferation by targeting SMAD4 [39], and miR-663a overexpression suppresses hepatic stellate cell proliferation by downregulating SMAD4 levels [40]. Based on the above results, $S M A D 4$ functions mostly as a positive regulator of cell proliferation. Moreover, the SMAD4 and TGF- $\beta$ signaling pathways play important roles in miRNA regulation of cell proliferation $[41,42]$. Notably, miR183 promotes preadipocyte adipogenesis by suppressing SMAD4 expression in goats [43], and myostatin/ SMAD4 signaling inhibits 3T3-L1 cell differentiation [44]. These findings demonstrate that the effects of SMAD4 on adipocyte differentiation vary in different cell types. However, in our study, SMAD4 was not identified as a target gene of miR-146a-5p during the differentiation phase of porcine intramuscular preadipocytes (Fig. S2A and B). Here, we revealed that miR-146a-5p is a novel miRNA that targets $S M A D 4$ to repress porcine intramuscular preadipocyte proliferation via the TGF- $\beta$ signaling pathway.

Furthermore, we confirmed through TargetScan 7.0 analysis, luciferase activity assay, and rescue experiments that during porcine intramuscular preadipocyte adipogenic differentiation, the target gene of miR146a-5p is TRAF6. As expected, miR-146a-5p targeted TRAF6 during cell differentiation, but not during proliferation (Fig. S2C and D). TRAF6 is a signal transduction factor that connects cell surface receptors with intracellular signal proteins. In addition to the inflammatory immune response, TRAF6 also 

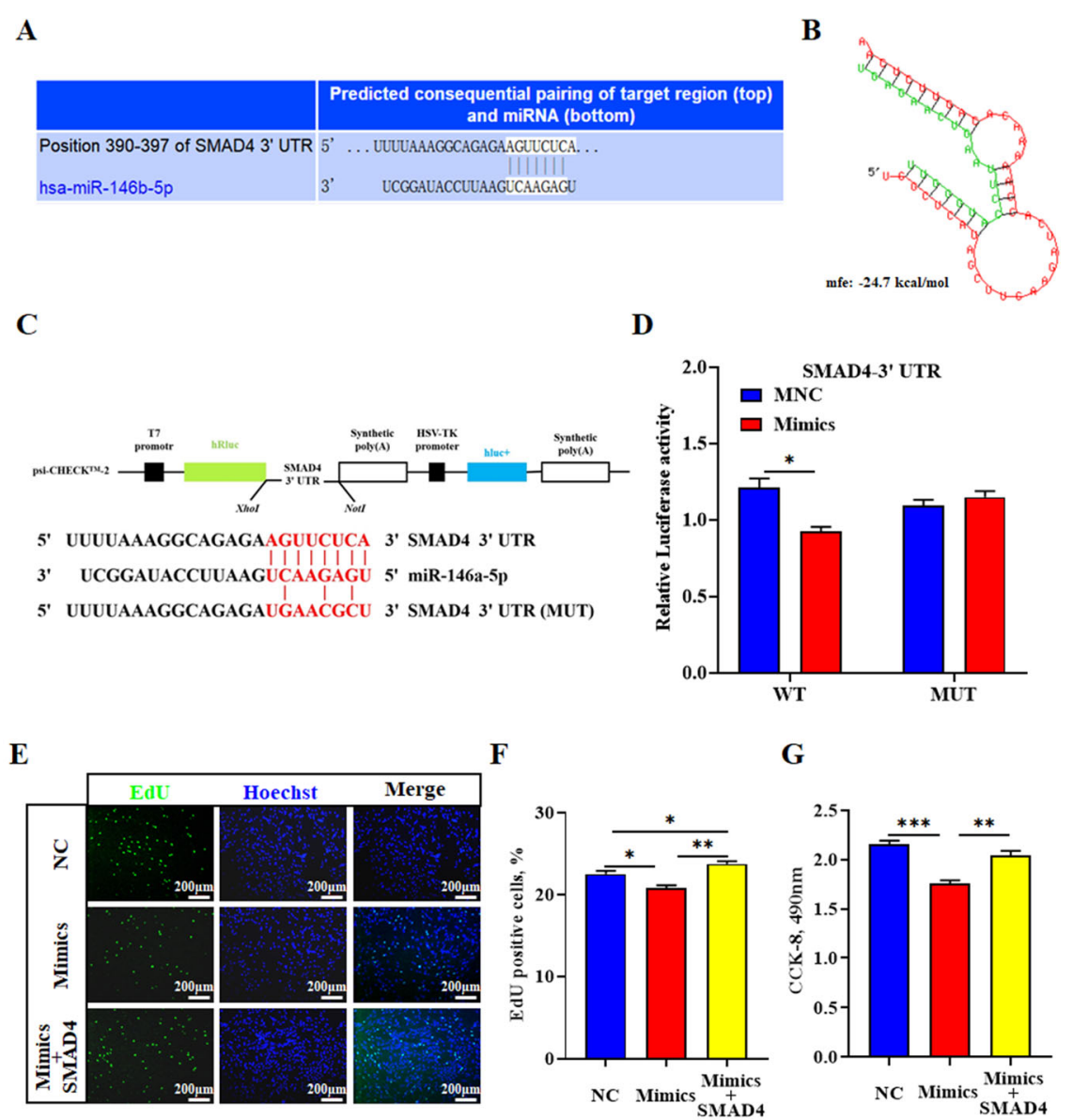

H

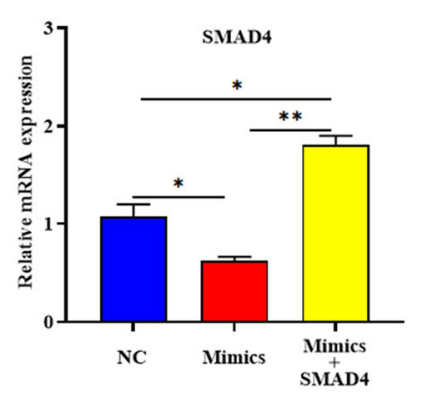

$\mathbf{J}$

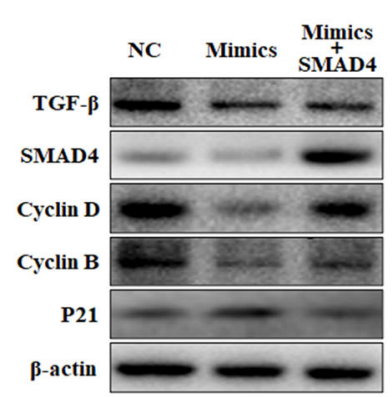

I

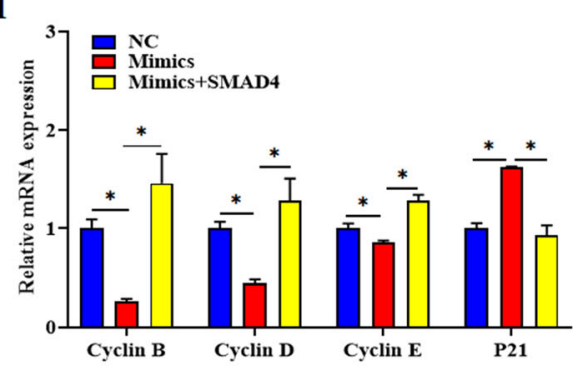

K

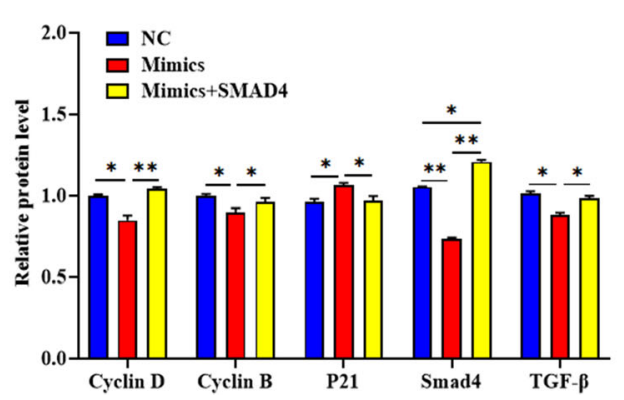

Fig. 4 (See legend on next page.) 
(See figure on previous page.)

Fig. 4 MiR-146a-5p targeting SMAD4 inhibits the proliferation of porcine intramuscular preadipocytes by the TGF- $\beta$ signaling pathway. a SMAD4 was predicted to be a target of miR-146a-5p by TargetScan software. b miR-146a-5p and SMAD4 3' UTR region base complementary pattern diagram. $\mathbf{c}$ WT and MUT psiCHECK-2.0-SMAD4 vectors. $\mathbf{d}$ Relative luciferase activity of SMAD4 responding to miR-146a-5p mimics. To verify that miR-146a-5p can function by targeting SMAD4, we co-treated cells with miR-146a-5p mimics and SMAD4 overexpression vector (500 ng, 6-well plate). e EdU staining assay. f Quantification ratio of EdU-positive cells/total cells. g CCK-8 analysis. h RT-qPCR was used to detect SMAD4 mRNA expression level. i Cell cycle genes cyclin B, cyclin D, cyclin E, and p21 expression level. $\mathbf{j}$ Western blot analysis of cyclin $E$, cyclin D, PCNA and p21. $\mathbf{k}$ Protein quantitative analysis of cyclin $E$, cyclin $D, P C N A$ and $p 21$. Values are expressed as the mean $\pm \operatorname{SEM}(n=3) .{ }^{*}, P<0.05 ;{ }^{* *}, P<0.01 ;{ }^{* *}, P<0.001$, versus NC

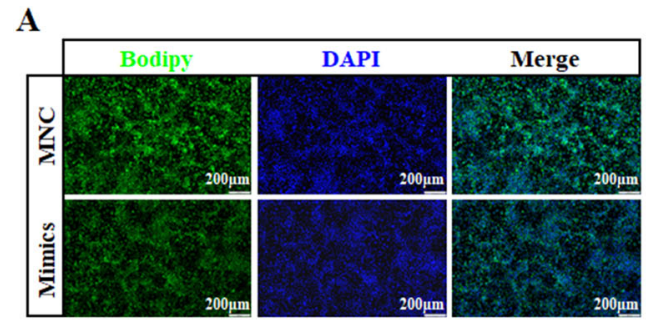

C

$\mathbf{B}$

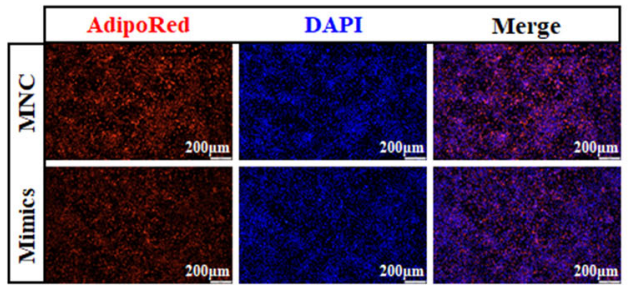

$\mathbf{E}$

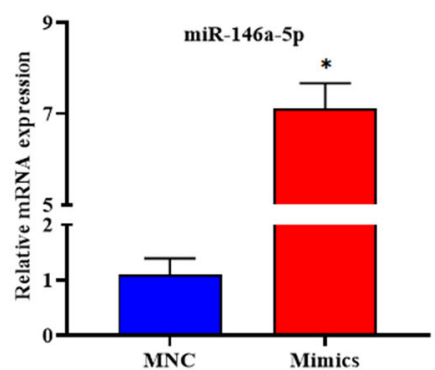

G

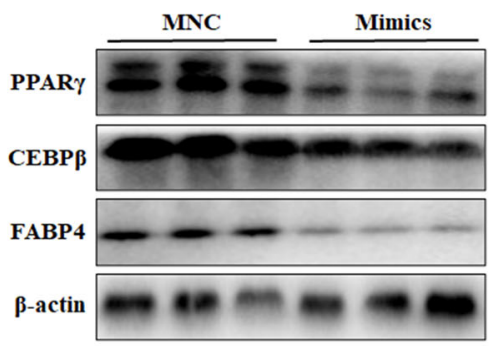

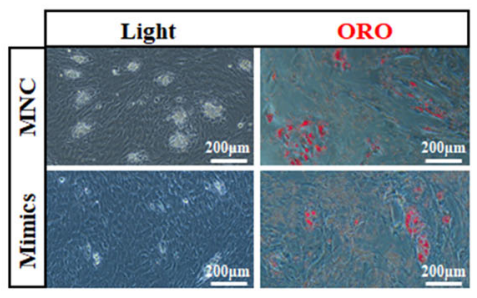

D

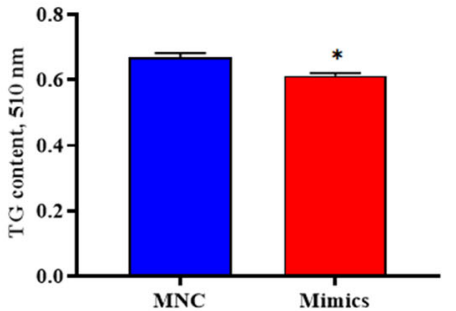

$\mathbf{F}$

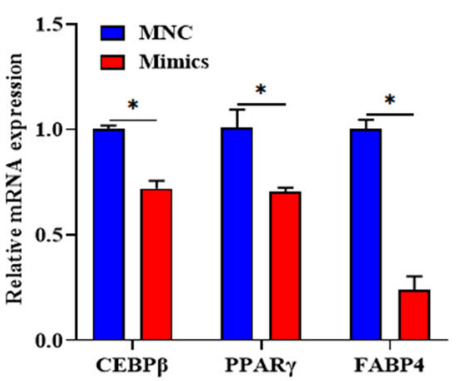

$\mathbf{H}$

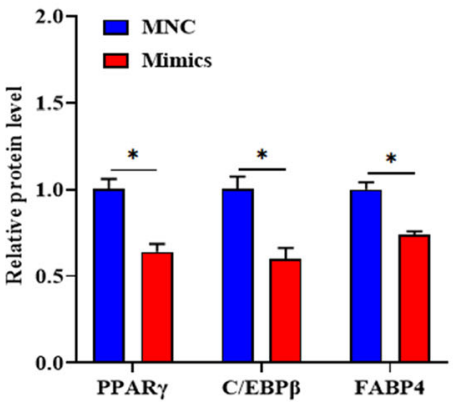

Fig. 5 MiR-146a-5p mimics suppresses porcine intramuscular preadipocyte differentiation. Porcine intramuscular preadipocyte were treated with miR-146a-5p mimics to induce differentiation on the $6^{\text {th }}$ day. $\mathbf{a}, \mathbf{b}$ Bodipy or AdipoRed staining was performed on lipid droplets. $\mathbf{c}$ White light field and oil red $\mathrm{O}$ stained lipid droplets. d After extracting oil red O with isopropanol, the OD value was detected, $510 \mathrm{~nm}$. e Overexpression efficiency of miR-146a-5p mimics after transfection for $6 \mathrm{~d}$. $\mathbf{f}$ RT-qPCR was used to detect the adipogenesis genes C/EBP $\beta$, PPARY, and FABP4. $\mathbf{g}$ Western blot analysis of C/EBPß, PPARY, and FABP4 after transfection with miR-146a-5p mimics. $\mathbf{h}$ Protein quantitative analysis of $\mathbf{g}$. Values are expressed as the mean $\pm \mathrm{SE}(n=3) .{ }^{*}, P<0.05$, versus MNC 
A

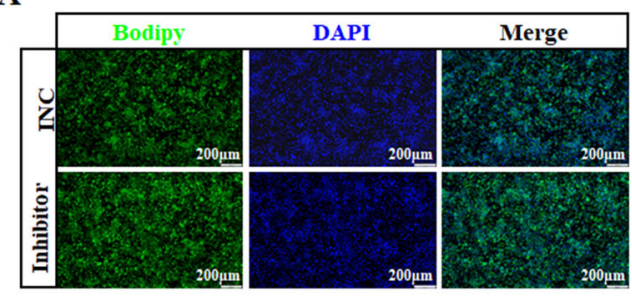

B

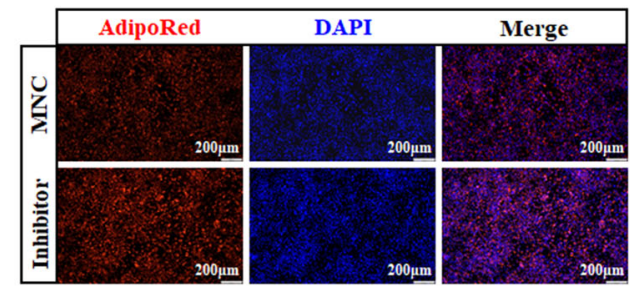

E

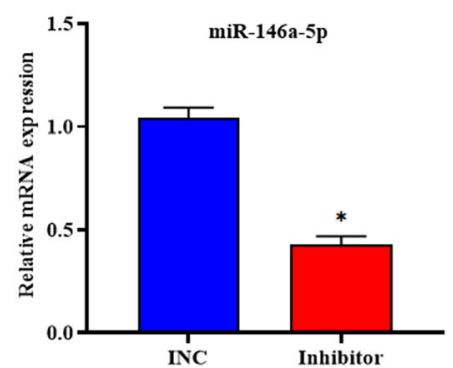

G

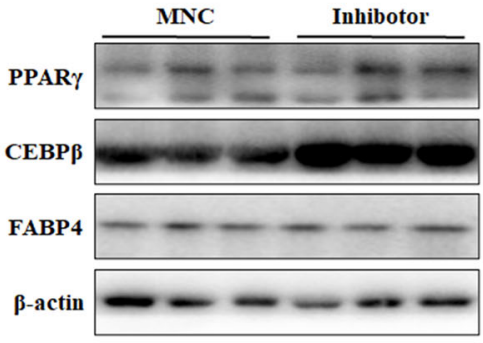

C

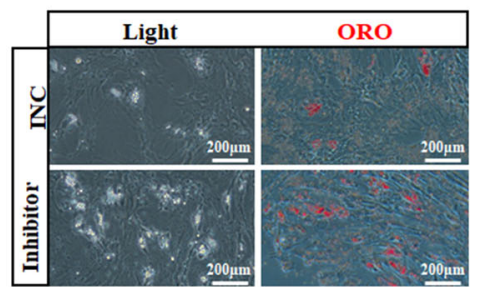

D

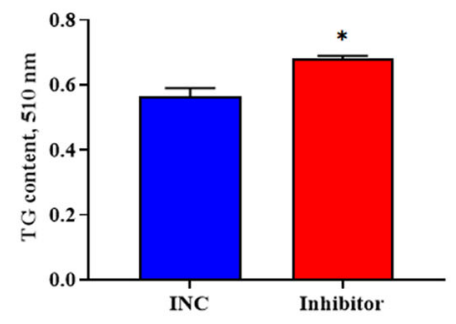

F

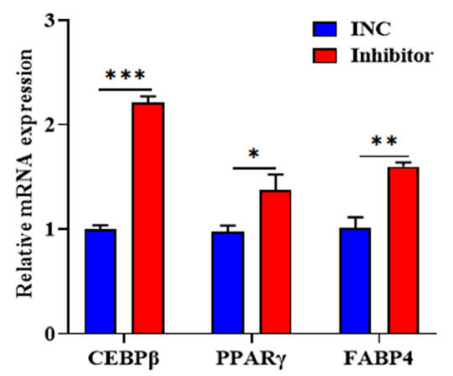

H

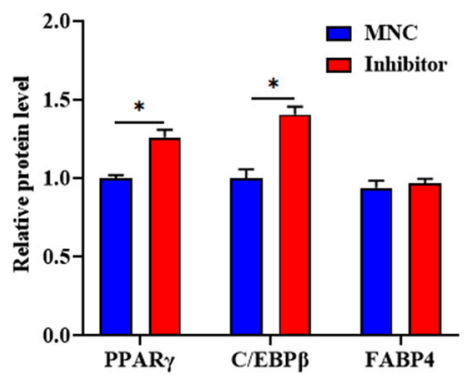

Fig. 6 MiR-146a-5p inhibitor accelerates porcine intramuscular preadipocyte differentiation. a Porcine intramuscular preadipocyte were treated with miR-146a-5p inhibitor to induce differentiation on the 6th day. $\mathbf{a}, \mathbf{b}$ Bodipy or AdipoRed staining was performed on lipid droplets. $\mathbf{c}$ White light field and oil red $\mathrm{O}$ stained lipid droplets. $\mathbf{d}$ After extracting oil red O with isopropanol, the OD value (510 nm) was detected. e Interference efficiency of miR-146a-5p inhibitor after transfection for $6 \mathrm{~d}$. $\mathbf{f}$ RT-qPCR was used to detect the adipogenesis genes C/EBP $\beta$, PPARY, and FABP4. $\mathbf{g}$ Western blot analysis of C/EBP $\beta$, PPARY, and FABP4 after transfection with miR-146a-5p inhibitor. $\mathbf{h}$ Protein quantitative analysis of $\mathbf{g}$. Values are expressed as the mean \pm SE $(n=3) .{ }^{*}, P<0.05 ;{ }^{* *}, P<0.01$, versus INC

regulates cell differentiation and survival [45]. Previous studies have shown that inhibiting the CD40TRAF6 interaction induces obesity by improving glucose tolerance and reducing the accumulation of immune cells into adipose tissue [46]. Moreover, green tea extracts reduced the adipose tissue weight of obese mice by reducing TRAF6 expression [47].
Interestingly, a significant reduction in wet weight and adipocyte hypertrophy was observe in epididymal WAT of adipocyte-specific TRAF6-KO mice on a high fat diet (HFD), which suggests TRAF6 inhibition in adipocytes could relieve the obesity induced by a HFD [19]. Therefore, inhibiting TRAF6 expression reduce the accumulation of fat to relieve obesity. However, 


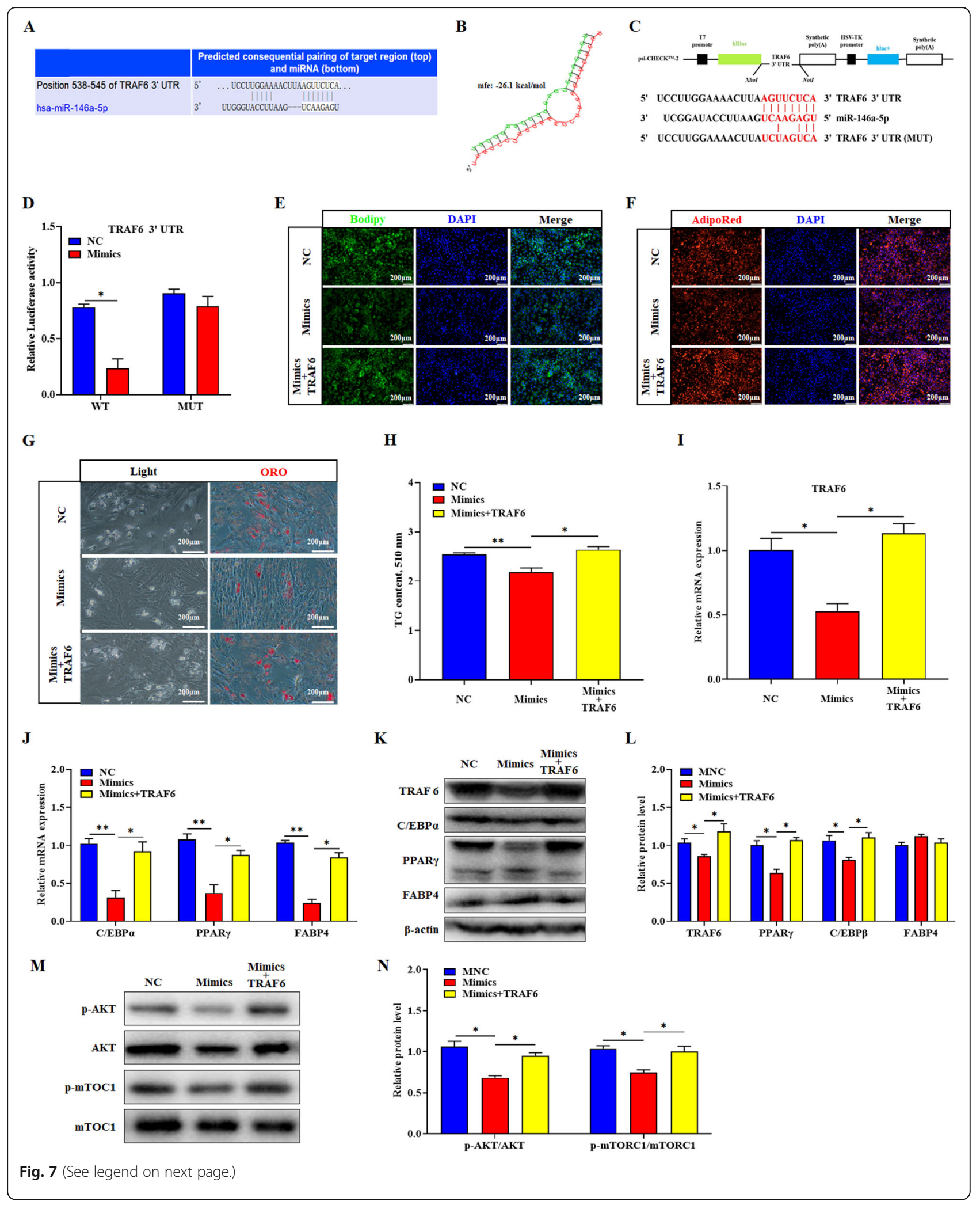


(See figure on previous page.)

Fig. 7 MiR-146a-5p targeting TRAF6 inhibits the differentiation of porcine intramuscular preadipocytes via the AKT/mTORC1 signaling pathway. a TRAF6 was predicted to be a target of miR-146a-5p by TargetScan software. $\mathbf{b}$ miR-146a-5p and TRAF6 3' UTR region base complementary pattern diagram. c WT and MUT psiCHECK-2.0-TRAF6 vectors. d Relative luciferase activity of TRAF6 responding to miR$146 a-5 p$ mimics. To verify that miR-146a-5p can function by targeting TRAF6, we co-treated cells with miR-146a-5p mimics and TRAF6 overexpression vector (500 ng per hole, 6-well plate). e, f Bodipy or AdipoRed staining was performed on lipid droplets. $\mathbf{g}$ White light field and oil red $\mathrm{O}$ stained lipid droplets. $\mathbf{h}$ After extracting oil red O with isopropanol, the OD value $(510 \mathrm{~nm})$ was detected. $\mathbf{i}, \mathbf{j}$ RT-qPCR was used to detect the TRAF6 and adipogenesis genes C/EBP $\beta$, PPARY, and FABP4. $\mathbf{k}$ Western blot analysis of TRAF6, C/EBP $\beta$, PPARY, and FABP4. I Protein quantitative analysis of $\mathbf{k}$. $\mathbf{m}$ Western blot analysis of AKT, $\mathrm{p}-A K T$, mTORC1, and $\mathbf{p}$-mTORC1. $\mathbf{n}$ Protein quantitative analysis of $\mathbf{m}$. Values are expressed as the mean \pm SE $(n=3) .{ }^{*}, P<0.05 ;{ }^{* *}, P<0.01$, versus NC

it is not clear whether inhibiting TRAF6 to prevent obesity is caused by affecting adipocyte differentiation. Notably, AKT/mTORC1 signaling, is downstream of TRAF6, is indispensable in the preadipocyte differentiation process $[21$, $48,49]$. In addition, the process of adipogenesis is often accompanied by cell inflammation. In our study, when the adipogenesis of porcine intramuscular preadipocyte was inhibited, the inflammatory factor NF- $\mathrm{kB}$ and its phosphorylation levels were also downregulated, and the adipogenic ability and inflammation were restored after the addition of the TRAF6 overexpression vector (Fig. S3A and B). In general, we found that miR-146a-5p targets TRAF6 to inhibit porcine intramuscular preadipocyte differentiation through regulating the AKT/mTORC1 signaling pathway.

\section{Conclusions}

In conclusion, miR-146a-5p targets SMAD4 to inhibit porcine intramuscular preadipocyte proliferation through the TGF- $\beta$ signaling pathway, and miR-146a-5p also targets TRAF6 to repress adipogenic differentiation via the $\mathrm{AKT} / \mathrm{mTORC1}$ signaling pathway (Fig. 8). These findings provide a novel miRNA biomarker for

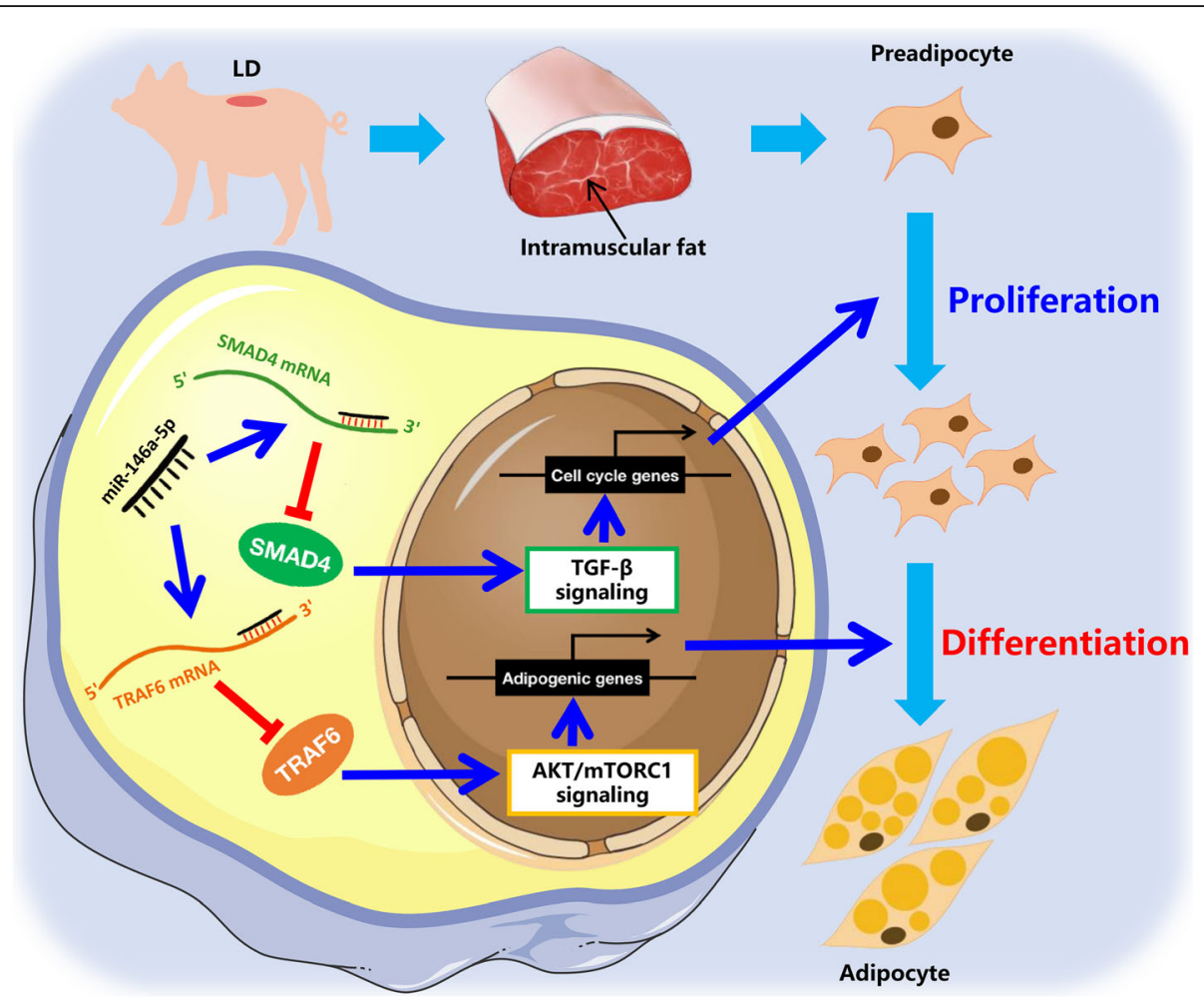

Fig. 8 A model depicting the role of miR-146a-5p in regulating porcine IMF adipogenesis. The intramuscular preadipocytes are derived from the pig's longest dorsal muscle. On the one hand, miR-146a-5p targets SMAD4 mRNA, inhibits the formation of signal transduction factors, inhibits TGF- $\beta$ signal transmission into the nucleus, and inhibits cell proliferation by inhibiting cell cycle related genes. On the other hand, miR-146a-5p directly targets TRAF6 mRNA to inhibit its translation and inhibits adipogenesis gene expression through the AKT/mTORC1 signaling pathway, thereby inhibiting adipogenesis 
modulating IMF content to enhance pork quality and help us to better understand the role and regulatory mechanism of miRNAs in IMF adipogenesis.

\section{Supplementary Information}

The online version contains supplementary material available at https://doi. org/10.1186/s40104-020-00525-3.

Additional file 1: Figure S1. Porcine intramuscular preadipocytes of different densities. A, white light field of newly seeded porcine intramuscular preadipocyte. B, white light field of porcine intramuscular preadipocyte which the density reached $50-60 \%$. C, white light field of porcine intramuscular preadipocyte which the density reached $90-100 \%$.

Additional file 2: Figure S2. The expression of TRAF6 and SMAD4 during the proliferation and differentiation of porcine intramuscular preadipocytes. A, western blot analysis of SMAD4 in differentiated porcine intramuscular adipocytes which transfected with miR-146a-5p mimics. B, protein quantitative analysis of A. C, western blot analysis of TRAF6 in proliferation porcine intramuscular adipocytes which transfected with miR-146a-5p mimics. D, protein quantitative analysis of $C$. Values are expressed as mean \pm SEM $(n=3)$

Additional file 3: Figure S3. The protein levels of NF-KB and $p-N F-k B$. A, western blot analysis of NF-KB and p-NF-KB in differentiated porcine intramuscular adipocytes. B, protein quantitative analysis of $A$. Values are expressed as mean $\pm \operatorname{SEM}(n=3) .{ }^{*}, P<0.05 ;{ }^{* *}, P<0.01$, versus MNC.

\section{Abbreviations}

IMF: Intramuscular fat; miRNAs: MicroRNAs; SMAD4: SMAD family member 4; TRAF6: TNF receptor associated factor 6; WAT: White adipose tissue; CDKs: Cyclindependent kinases; CKIs: CDK inhibitors; PPARY: Peroxisome proliferator-activated receptor $\gamma$; C/EBP: CCAAT/enhancer binding protein; FABP4: Fatty acid binding protein 4; LPL: Lipoprotein lipase; LD: Longissimus dorsi; SWAT: Subcutaneous white adipose tissue; PBS: Phosphate buffer saline; RT-qPCR: Real-time quantitative PCR; MNC: Mimics negative control; INC: Inhibitor negative control; DLR: Dualluciferase reporter; TG: Triglycerides; PI: Propidium iodide

\section{Acknowledgments}

We thank all the members of the Animal Fat Deposition and Muscle Development Laboratory of the College of Animal Science and Technology, Northwest A\&F University who make efforts to these experiments. Zhang Que especially wishes to thank the support and encouragement of Ren Fa.

\section{Authors' contributions}

Zhang Que, Cai Rui, Tang Guorong, Zhang Wanrong conducted the experiment; Zhang Que and Cai Rui collected and analyzed the data; Tang Guorong, Zhang Wanrong, and Pang Weijun helped with the discussion; Zhang Que, Cai Rui and Pang Weijun designed the experiment; Zhang Que Cai Rui and Pang Weijun wrote and revised the manuscript; The authors read and approved the final manuscript.

\section{Funding}

This work was supported by grants from the National Natural Science Foundation (31872979, 31572366), the National Key Research and Development Program of China (2017YFD0502002), and the National Basic Research Programs of China (2015CB943102).

\section{Availability of data and materials}

All data generated or analyzed during this study are available from the corresponding author by request.

\section{Ethics approval and consent to participate}

All experimental procedures were performed according to the Guide for Northwest A\&F University Animal Care Committee. The experimental protocol was approved by the Departmental Animal Ethics Committee of Northwest A\&F University (14-233, 10 December 2014). As suggested by the animal welfare protocol, all efforts were made to reduce animal suffering and to use only the number of animals required to produce dependable scientific data.
Consent for publication

Not applicable.

\section{Competing interests}

The authors have declared no conflict of interest.

Received: 25 June 2020 Accepted: 16 November 2020

Published online: 03 February 2021

\section{References}

1. Fernandez X, Monin G, Talmant A, Mourot J, Lebret B. Influence of intramuscular fat content on the quality of pig meat - 1. Composition of the lipid fraction and sensory characteristics of $\mathrm{m}$. longissimus lumborum. Meat Sci. 1999:53(1):59-65.

2. Nogalski Z, Pogorzelska-Przybyłek P, Białobrzewski I, Modzelewska-Kapituła M, Sobczuk-Szul M, Purwin C, et al. Estimation of the intramuscular fat content of $\mathrm{m}$. longissimus thoracis in crossbred beef cattle based on live animal measurements. Meat Sci. 2017;125:121-7.

3. Chen L, Zhang Y, Chen H, Zhang X, Liu X, He Z, et al. Comparative transcriptome analysis reveals a more complicated adipogenic process in intramuscular stem cells than that of subcutaneous vascular stem cells. J Agric Food Chem. 2019;67(16):4700-8.

4. Petrus P, Mejhert N, Corrales P, Lecoutre S, Li Q, Maldonado E, et al. Transforming growth factor- $\beta 3$ regulates adipocyte number in subcutaneous white adipose tissue. Cell Rep. 2018;25(3):551-60.e5.

5. Sun Y, Cai R, Wang Y, Zhao R, Qin J, Pang W. A newly identified IncRNA IncIMF4 controls adipogenesis of porcine intramuscular preadipocyte through attenuating autophagy to inhibit lipolysis. Animals (Basel). 2020; 10(6):E926.

6. Nobre JL, Lisboa PC, Carvalho JC, Martins MR, Vargas S, Barja-Fidalgo C, et al Leptin blocks the inhibitory effect of vitamin D on adipogenesis and cell proliferation in 3T3-L1 adipocytes. Gen Comp Endocrinol. 2018;266:1-8.

7. Lujambio A, Lowe SW. The microcosmos of cancer. Nature. 2012;482(7385): 347-55

8. Maurizi G, Babini L, Della GL. Potential role of microRNAs in the regulation of adipocytes liposecretion and adipose tissue physiology. J Cell Physiol. 2018:233(12):9077-86.

9. Xu K, Ji M, Huang X, Peng Y, Wu W, Zhang J. Differential regulatory roles of microRNAs in porcine intramuscular and subcutaneous adipocytes. J Agric Food Chem. 2020;68(13):3954-62

10. Khan R, Raza SHA, Junjvlieke Z, Wang X, Wang H, Cheng G, et al. Bta-miR149-5p inhibits proliferation and differentiation of bovine adipocytes through targeting CRTCs at both transcriptional and posttranscriptional levels. J Cell Physiol. 2020;235(7-8):5796-810.

11. Du J, Zhang P, Gan M, Zhao X, Xu Y, Li Q, et al. MicroRNA-204-5p regulates 3T3-L1 preadipocyte proliferation, apoptosis and differentiation. Gene. 2018; 668:1-7

12. Xing $\mathrm{K}$, Zhao $\mathrm{X}, \mathrm{Ao} \mathrm{H}$, Chen $\mathrm{S}$, Yang $\mathrm{T}$, Tan $\mathrm{Z}$, et al. Transcriptome analysis of miRNA and mRNA in the livers of pigs with highly diverged backfat thickness. Sci Rep. 2019:9(1):16740.

13. Mohd Faheem M, Rasool RU, Ahmad SM, Jamwal VL, Chakraborty S, Katoch A, et al. Par-4 mediated Smad4 induction in PDAC cells restores canonical TGF-beta / Smad4 axis driving the cells towards lethal EMT. Eur J Cell Biol. 2020;99(4):151076

14. Massagué J, Gomis RR. The logic of TGFbeta signaling. FEBS Lett. 2006; 580(12):2811-20

15. Zhao M, Mishra L, Deng CX. The role of TGF-beta/SMAD4 signaling in cancer. Int J Biol Sci. 2018;14(2):111-23.

16. Wan $R, X u X, M a L$, Chen $Y$, Tang L, Feng J. Novel alternatively spliced variants of smad4 expressed in TGF- $\beta$-induced EMT regulating proliferation and migration of A549 cells. Onco Targets Ther. 2020;13:2203-13.

17. Zuo Y, Lu Y, Xu Q, Sun D, Liang X, Li X, et al. Inhibitory effect of dihydromyricetin on the proliferation of JAR cells and its mechanism of action. Oncol Lett. 2020:20(1):357-63.

18. Zhou J, Hu M, Wang F, Song M, Huang Q, Ge B. MiR-224 controls human colorectal cancer cell line HCT116 proliferation by targeting Smad4. Int J Med Sci. 2017;14(10):937-42

19. Gallot YS, McMillan JD, Xiong G, Bohnert KR, Straughn AR, Hill BG, et al. Distinct roles of TRAF6 and TAK1 in the regulation of adipocyte survival, thermogenesis program, and high-fat diet-induced obesity. Oncotarget. 2017;8(68):112565-83 
20. Fu TM, Shen C, Li Q, Zhang P, Wu H. Mechanism of ubiquitin transfer promoted by TRAF6. Proc Natl Acad Sci U S A. 2018;115(8):1783-8.

21. Yang WL, Wang J, Chan CH, Lee SW, Campos AD, Lamothe B, et al. The E3 ligase TRAF6 regulates Akt ubiquitination and activation. Science. 2009; 325(5944):1134-8.

22. Wang Y, Zhou C, Huo J, Ni Y, Zhang P, Lu C, et al. TRAF6 is required for the GM-CSF-induced JNK, p38 and Akt activation. Mol Immunol. 2015;65(2):224-9.

23. Gray CW, Coster ACF. Crosstalk in transition: the translocation of Akt. J Math Biol. 2019;78(4):919-42.

24. Li DG, Li JL, Sun DQ, Sun XB, Sun XG, Liu Q. Lentinan depresses 3T3-L1 fat cell formation by inhibiting PPARY/AKT signaling pathway. Genet Mol Res. 2015;14(3):8084-90.

25. Xu J, Liao K. Protein kinase B/AKT 1 plays a pivotal role in insulin-like growth factor-1 receptor signaling induced 3T3-L1 adipocyte differentiation. J Biol Chem. 2004;279(34):35914-22.

26. Baudry A, Yang ZZ, Hemmings BA. PKBalpha is required for adipose differentiation of mouse embryonic fibroblasts. J Cell Sci. 2006;119(5):889-97.

27. Wullschleger $\mathrm{S}$, Loewith $\mathrm{R}$, Hall MN. TOR signaling in growth and metabolism. Cell. 2006;124(3):471-84.

28. Minard AY, Tan SX, Yang P, Fazakerley DJ, Domanova W, Parker BL, et al. mTORC1 is a major regulatory node in the FGF21 signaling network in adipocytes. Cell Rep. 2016 Sep 27;17(1):29-36.

29. Jung $\mathrm{CH}$, Kim H, Ahn J, Jeon TI, Lee DH, Ha TY. Fisetin regulates obesity by targeting mTORC1 signaling. J Nutr Biochem. 2013;24(8):1547-54.

30. Martin SK, Fitter S, Dutta AK, Matthews MP, Walkley CR, Hall MN, et al. Brief report: the differential roles of MTORC1 and mTORC2 in mesenchymal stem cell differentiation. Stem Cells. 2015;33(4):1359-65.

31. Wang $Q, Q i$, Wang J, Huang $W, W u Y$, Huang $X$, et al. Differential expression profile of miRNAs in porcine muscle and adipose tissue during development. Gene. 2017;618:49-56.

32. Chen FF, Xiong $Y$, Peng $Y$, Gao $Y$, Qin J, Chu GY, et al. miR-425-5p Inhibits differentiation and proliferation in porcine intramuscular preadipocytes. Int J Mol Sci. 2017;18(10):2101

33. Sun X, Cui S, Fu X, Liu C, Wang Z, Liu Y. MicroRNA-146-5p promotes proliferation, migration and invasion in lung cancer cells by targeting claudin-12. Cancer Biomark. 2019;25(1):89-99.

34. Xiao WZ, Lu AQ, Liu XW, Li Z, Zi Y, Wang ZW. Role of miRNA-146 in proliferation and differentiation of mouse neural stem cells. Biosci Rep. 2015;35(5):e00245.

35. Cai R, Qimuge N, Ma ML, Wang YQ, Tang GR, Zhang Q, et al. MicroRNA-664$5 p$ promotes myoblast proliferation and inhibits myoblast differentiation by targeting serum response factor and Wnt1. J Biol Chem. 2018;293(50): 19177-90.

36. Peng Y, Chen FF, Ge J, Zhu JY, Shi XE, Li X, et al. MiR-429 inhibits differentiation and promotes proliferation in porcine preadipocytes. Int J Mol Sci. 2016;17(12):2047.

37. Song CC, Yang ZX, Dong D, Xu JW, Wang J, Li H, et al. MiR-483 inhibits bovine myoblast cell proliferation and differentiation via IGF1/PI3K/AKT signal pathway. J Cell Physiol. 2019;234(6):9839-48.

38. Li X, Li K, Yu G, Yu C, Liu C. miR-342-5p inhibits expression of Bmp7 to regulate proliferation, differentiation and migration of osteoblasts. Mol Immunol. 2019:114:251-9.

39. Zhou J, Zhang X, Li W, Chen Y. MicroRNA-145-5p regulates the proliferation of epithelial ovarian cancer cells via targeting SMAD4. J Ovarian Res. 2020; 13(1):54

40. Guo XX, Yang WN, Dong BS, Shang JW, Su SB, Yan XL, et al. Glycyrrhetinic acid-induced miR-663a alleviates hepatic stellate cell activation by attenuating the TGF- $\beta /$ Smad signaling pathway. Evid Based Complement Alternat Med. 2020;2020:3156267.

41. Zhang Z, Wang W, Liu JB, Wang Y, Hao JD, Huang YJ, et al. Ssc-miR-204 regulates porcine preadipocyte differentiation and apoptosis by targeting TGFBR1 and TGFBR2. J Cell Biochem. 2020;121(1):609-20.

42. Stewart A, Guan HY, Yang KP. BMP-3 promotes mesenchymal stem cell proliferation through the TGF-beta/Activin signaling pathway. J Cell Physiol. 2010;223(3):658-66.

43. Zhao W, Yang H, Li J, Chen Y, Cao J, Zhong T, et al. MiR-183 promotes preadipocyte differentiation by suppressing Smad4 in goats. Gene. 2018; 666:158-64

44. Liu K, Zhang X, Wei W, Liu X, Tian Y, Han H, et al. Myostatin/SMAD4 signaling-mediated regulation of miR-124-3p represses glucocorticoid receptor expression and inhibits adipocyte differentiation. Am J Physiol Endocrinol Metab. 2019:316(4):E635-45.

45. Walsh MC, Lee J, Choi Y. Tumor necrosis factor receptor- associated factor 6 (TRAF6) regulation of development, function, and homeostasis of the immune system. Immunol Rev. 2015;266(1):72-92.

46. Van den Berg SM, Seijkens TT, Kusters PJ, Zarzycka B, Beckers L, den Toom $M$, et al. Blocking CD40-TRAF6 interactions by small-molecule inhibitor 6860766 ameliorates the complications of diet-induced obesity in mice. Int J Obes. 2015;39(5):782-90.

47. Cunha CA, Lira FS, Rosa Neto JC, Pimentel GD, Souza Gl, da Silva CM, et al. Green tea extract supplementation induces the lipolytic pathway, attenuates obesity, and reduces low-grade inflammation in mice fed a highfat diet. Mediat Inflamm. 2013;2013:635470.

48. Jia Y, Wu C, Kim J, Kim B, Lee SJ. Astaxanthin reduces hepatic lipid accumulations in high-fat-fed C57BL/6J mice via activation of peroxisome proliferator-activated receptor (PPAR) alpha and inhibition of PPAR gamma and Akt. J Nutr Biochem. 2016;28:9-18.

49. Liu Z, Gan L, Liu G, Chen Y, Wu T, Feng F, et al. Sirt1 decreased adipose inflammation by interacting with Akt2 and inhibiting mTOR/S6K1 pathway in mice. J Lipid Res. 2016;57(8):1373-81.

\section{Ready to submit your research? Choose BMC and benefit from:}

- fast, convenient online submission

- thorough peer review by experienced researchers in your field

- rapid publication on acceptance

- support for research data, including large and complex data types

- gold Open Access which fosters wider collaboration and increased citations

- maximum visibility for your research: over $100 \mathrm{M}$ website views per year

At $\mathrm{BMC}$, research is always in progress.

Learn more biomedcentral.com/submissions 